Supporting Information

\title{
Effect of Co-surfactant on Structure and Properties of Polymerized High Internal Phase Emulsions (PolyHIPEs)
}

\author{
Muchu Zhou, Reza Foudazi* \\ Department of Chemical and Materials Engineering, New Mexico State University, Las Cruces, \\ NM 88003, USA
}

*Corresponding author. Email: rfoudazi@nmsu.edu. Tel: 1-(575)-6463691. 
Table S1. Typical polyHIPE formula

\begin{tabular}{|c|c|c|c|}
\hline & Component & Amount, wt $\%$ & Volume, \% \\
\hline \multirow{3}{*}{ Organic phase } & BA & 60.0 & 63.2 \\
\cline { 2 - 4 } & EGDMA & 20.0 & 17.8 \\
\cline { 2 - 4 } & TEMED & $0.001 \mathrm{~mL} / 4 \mathrm{~mL} \mathrm{HIPE}$ \\
\hline \multirow{2}{*}{$\begin{array}{c}\text { Aqueous } \\
\text { phase }\end{array}$} & Water & 94.0 & 97.1 \\
\cline { 2 - 4 } & $\mathrm{NaCl}$ & 5.0 & 2.4 \\
\hline \multirow{2}{*}{ Surfactant(s) } & APS & 1.0 & 0.5 \\
\hline
\end{tabular}

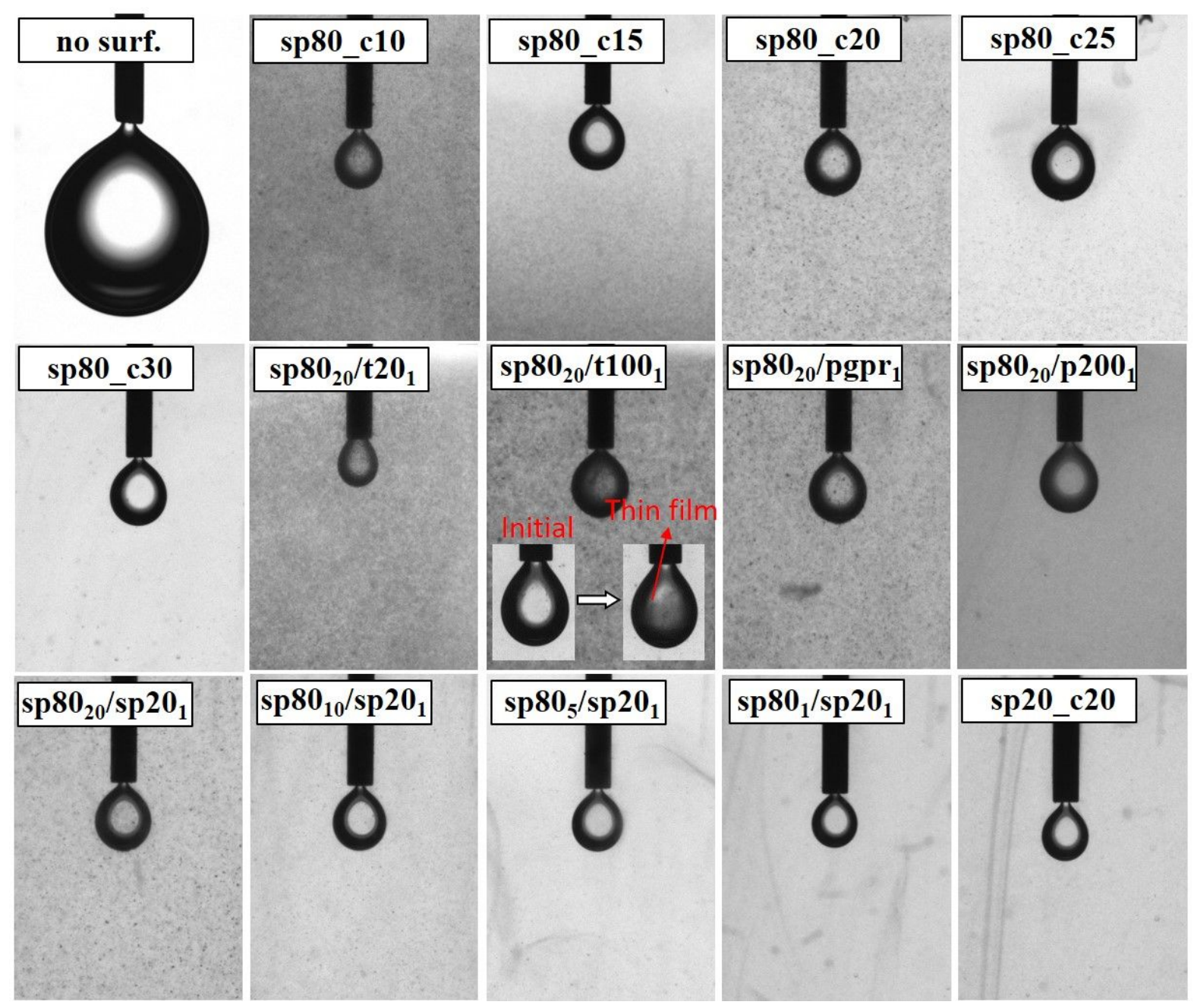

Figure S1. Aqueous phase pendent drops in the oil phase used to obtain the interfacial tension. 
Table S2. Concentration range of surfactant(s) for monomer solution becomes cloudy

\begin{tabular}{|c|c|c|c|c|c|}
\hline \multirow{2}{*}{ Status } & \multicolumn{5}{|c|}{ Concentration range, $\mathrm{wt} \%$} \\
\cline { 2 - 6 } & $\mathrm{sp} 80$ & $\mathrm{sp} 80_{20} / \mathrm{sp} 20_{1}$ & $\mathrm{sp} 80_{10} / \mathrm{sp} 20_{1}$ & $\mathrm{sp} 80_{1} / \mathrm{sp}_{2} 0_{1}$ & $\mathrm{sp} 20$ \\
\hline Clear & $0.0-2.7$ & $0.0-2.4$ & $0.0-1.9$ & $0.0-0.9$ & $0.0-0.7$ \\
\hline $\begin{array}{c}\text { Clear but light } \\
\text { yellow }\end{array}$ & $2.8-3.4$ & $2.5-3.1$ & $2.0-2.6$ & - & - \\
\hline Cloudy & $>=3.5$ & $>=3.2$ & $>=2.7$ & $>=1.0$ & $>=0.8$ \\
\hline
\end{tabular}

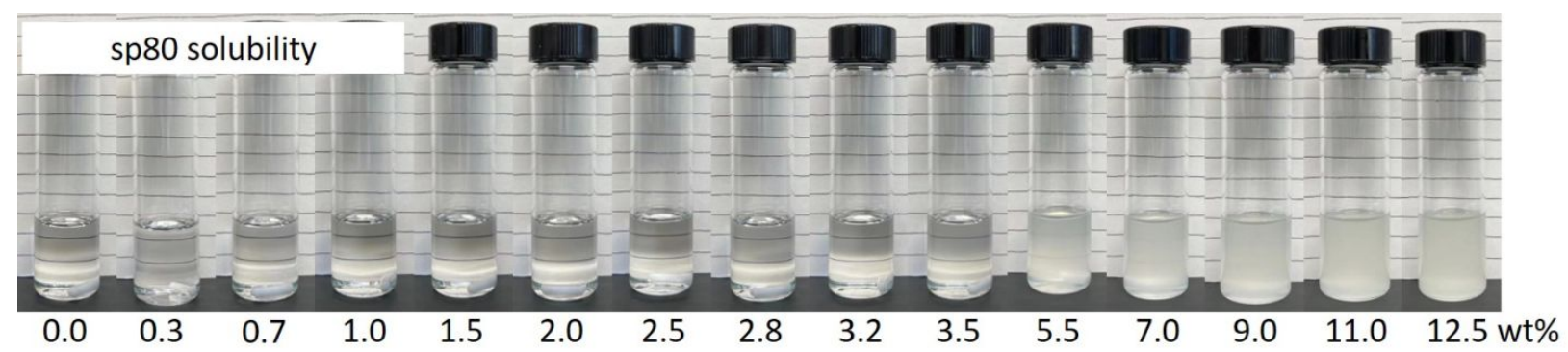

Figure S2. Solubility of surfactant Span 80 in the BA/EGDMA (BA and EGDMA ratio: 3/1)

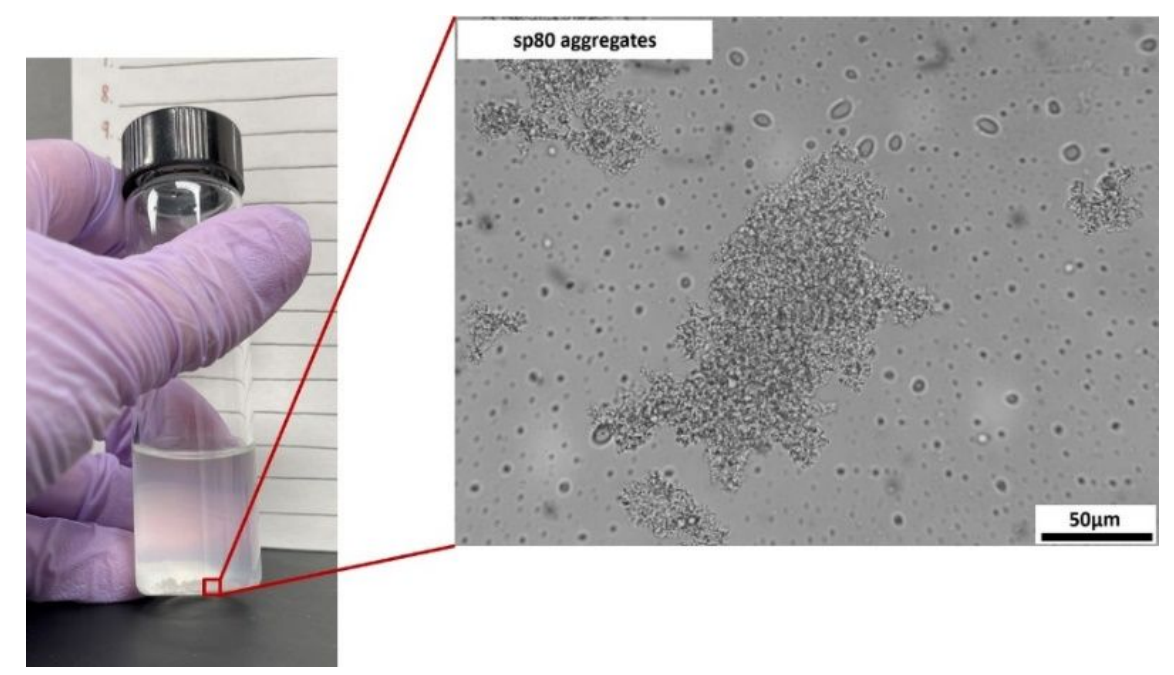

Figure S3. Aggregates formed for mixture of BA/EGDMA/Span 80 (concentration: 12.5wt\%) 


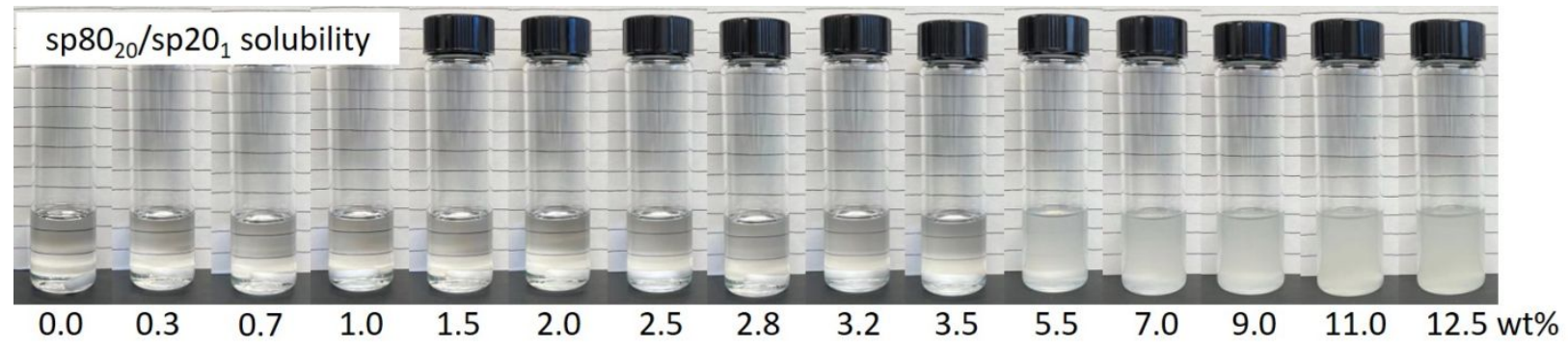

Figure S4. Solubility of surfactant Span 80/Span 20 in the BA/EGDMA (BA and EGDMA ratio: 3/1, Span 80 and Span 20 ratio: 20/1)

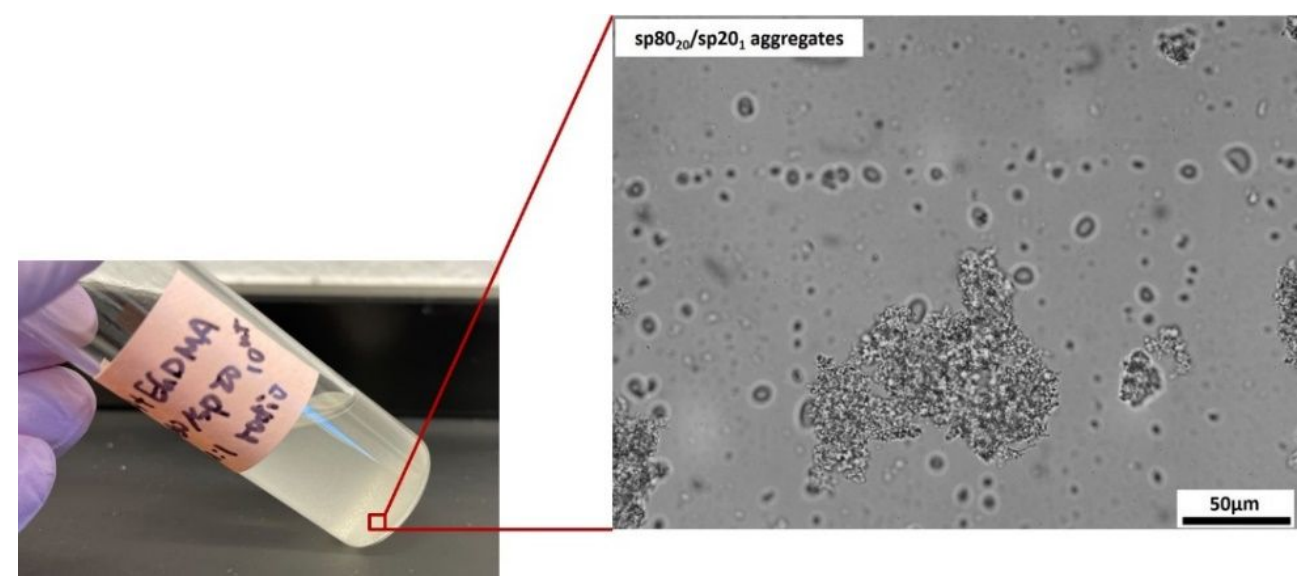

Figure S5. Aggregates formed for mixture of BA/EGDMA/Span 80/Span 20 (concentration: $12.5 \mathrm{wt} \%$, Span 80 and Span 20 ratio: $20 / 1$ )

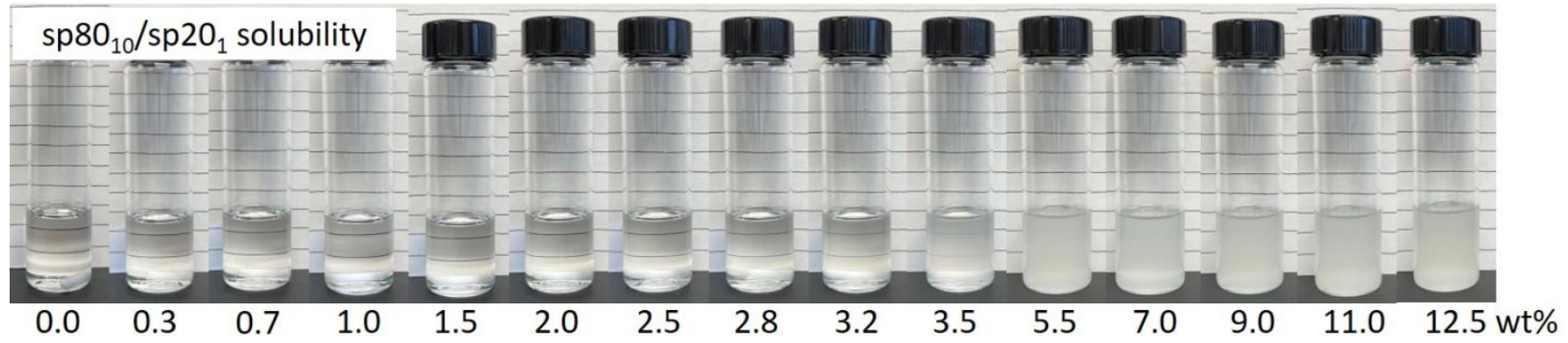

Figure S6. Solubility of surfactant Span 80/Span 20 in the BA/EGDMA (BA and EGDMA ratio: 3/1, Span 80 and Span 20 ratio: 10/1) 


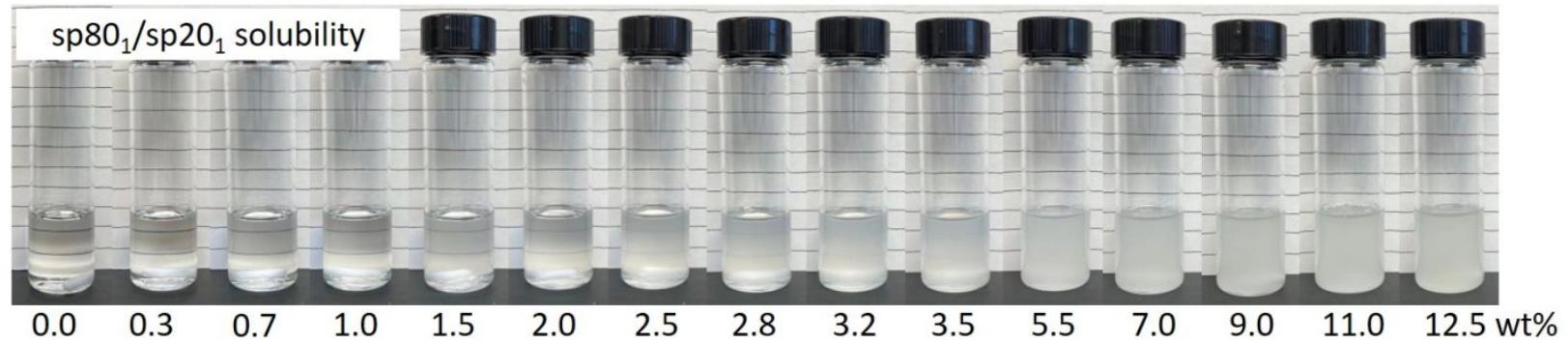

Figure S7. Solubility of surfactant Span 80/Span 20 in the BA/EGDMA (BA and EGDMA ratio: 3/1, Span 80 and Span 20 ratio: 1/1)

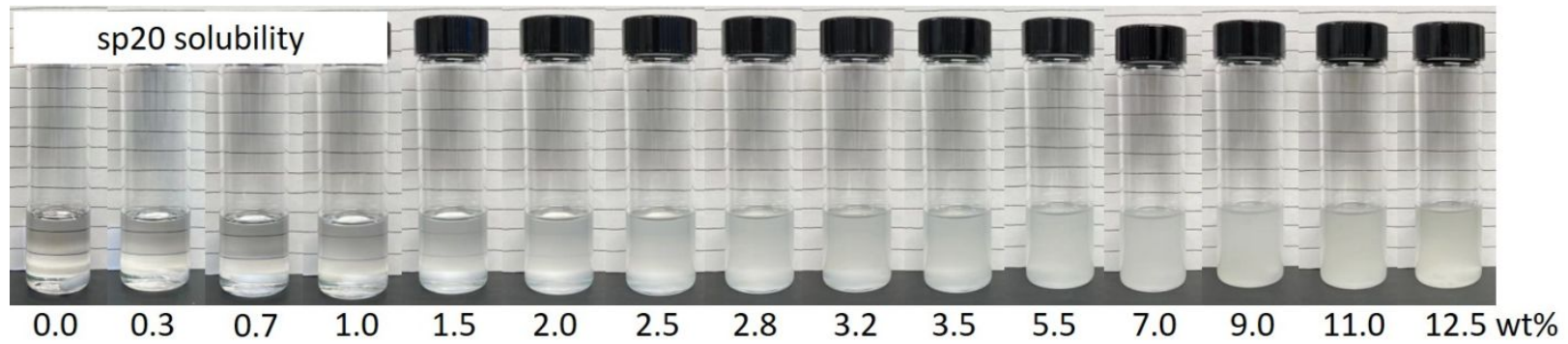

Figure S8. Solubility of surfactant Span 20 in the BA/EGDMA (BA and EGDMA ratio: 3/1)

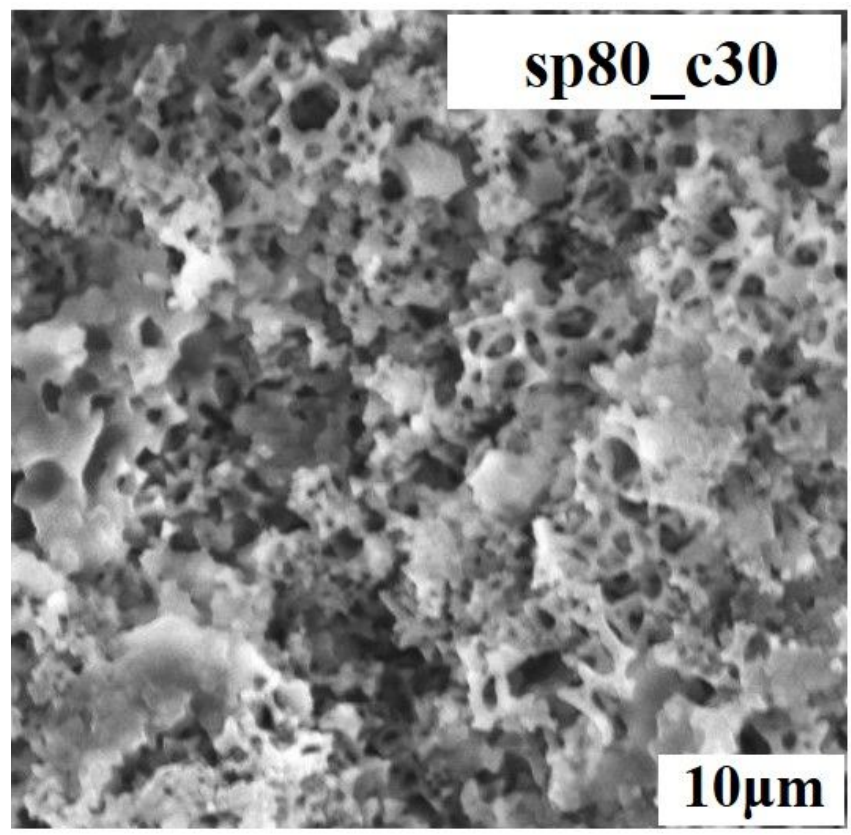

Figure S9. SEM image of sample sp80_c30 showing the structure collapse 


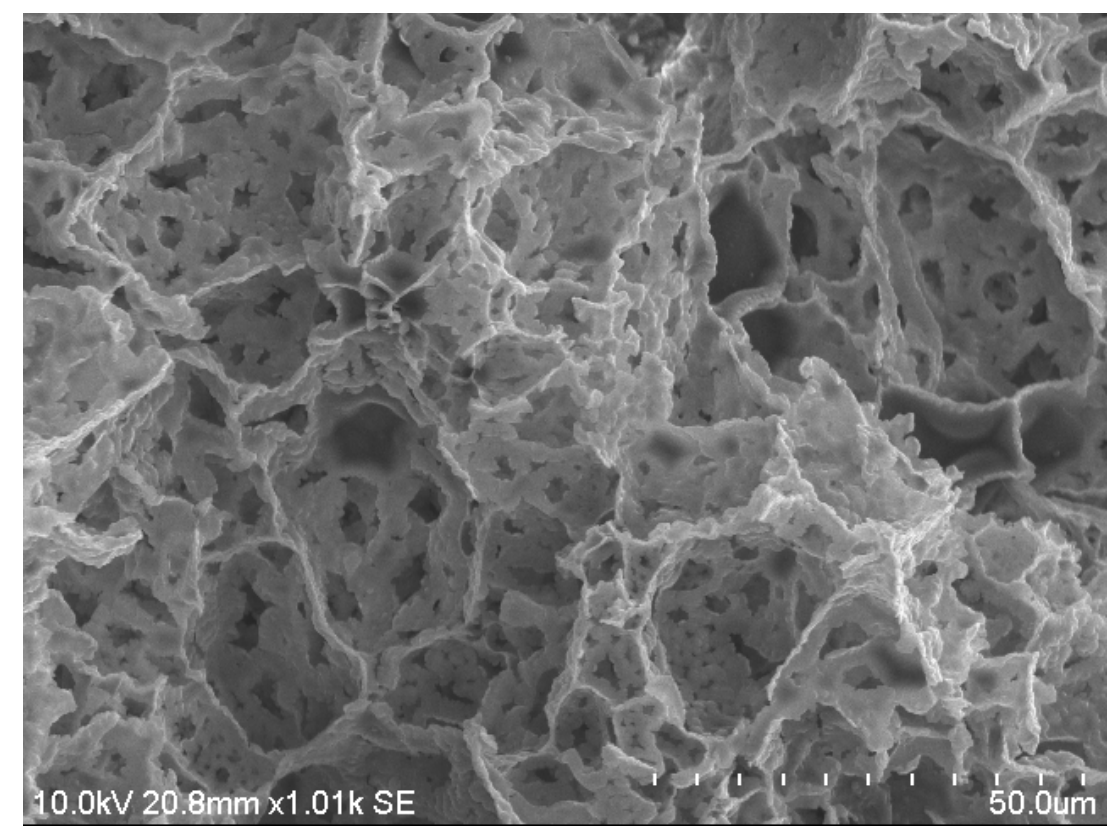

Figure S10. SEM image of polyHIPE sp80_c10 showing the relatively large windows 
A

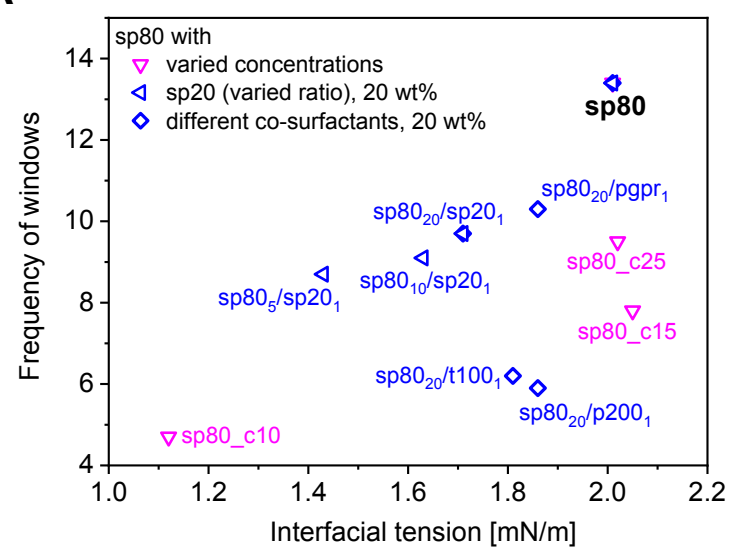

B

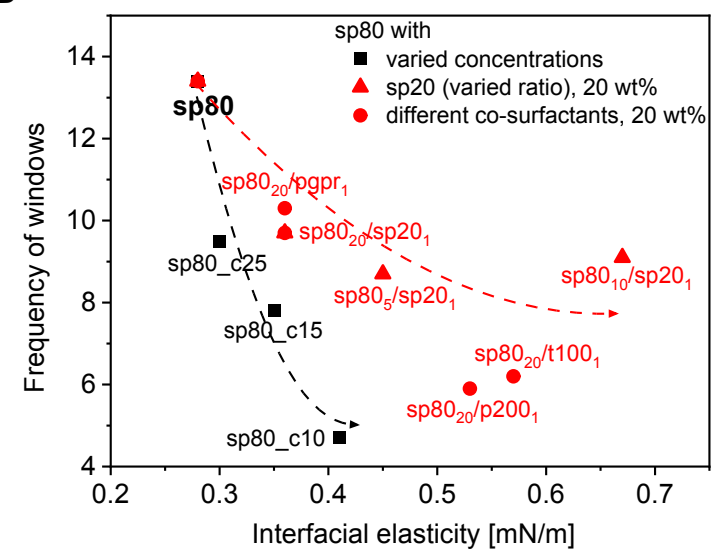

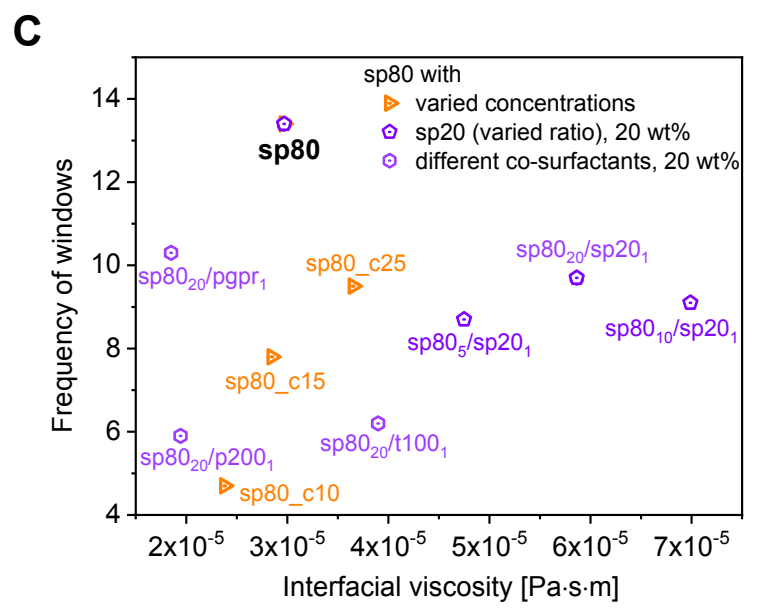

Figure S11. Dependance of window frequency on the interfacial properties 